\title{
Diagnosis of Meckel's diverticulum at the age of 54 by capsule endoscopy
}

We report the case of a 54-year-old man who presented with hematochezia and acute anemia (hemoglobin level $5 \mathrm{~g} / \mathrm{dL}$ ). Upper endoscopy and colonoscopy were negative. Capsule endoscopy (Pillcam SB3; Given Imaging, Yoqneam, Israel) performed 7 days after the bleeding episode revealed a double lumen image in the ileum ( $\triangleright$ Video 1$)$. No active bleeding was found. A probable diagnosis of Meckel's diverticulum was suggested. Technetium-99m pertechnetate scintigraphy (Meckel's scan) was negative. The patient was referred for surgery for Meckel's diverticulectomy. The Meckel's diverticulum was in the ileum, $40 \mathrm{~cm}$ proximal to the ileocecal valve, and measured $4 \mathrm{~cm}$ ( Fig. 1, $>$ Fig. 2). Histological findings confirmed Meckel's diverticulum.

Meckel's diverticulum is the most frequent gastrointestinal malformation; its prevalence has been estimated at $2 \%$ in the general population. It occurs in the antimesenteric region, in the last 60$100 \mathrm{~cm}$ of the ileum. Symptomatic Meckel's diverticulum is described as a condition found predominantly in children and adolescents, and as infrequent in adults over 40 years old [1,2]. Gastrointestinal bleeding has been described as one of the most frequent clinical manifestations. Generally, conventional imaging procedures have not suggested the diagnosis of Meckel's diverticulum, and some publications have reported that the sensitivity and specificity of Meckel's scan are low in adults ( $62 \%$ and $9 \%$ respectively). Capsule endoscopy is a useful diagnostic test for Meckel's diverticulum. Double lumen is the most frequent finding, followed by polypoid structure and circumferential ulceration [2-4].

Endoscopy_UCTN_Code_CCL_1AC_2AF

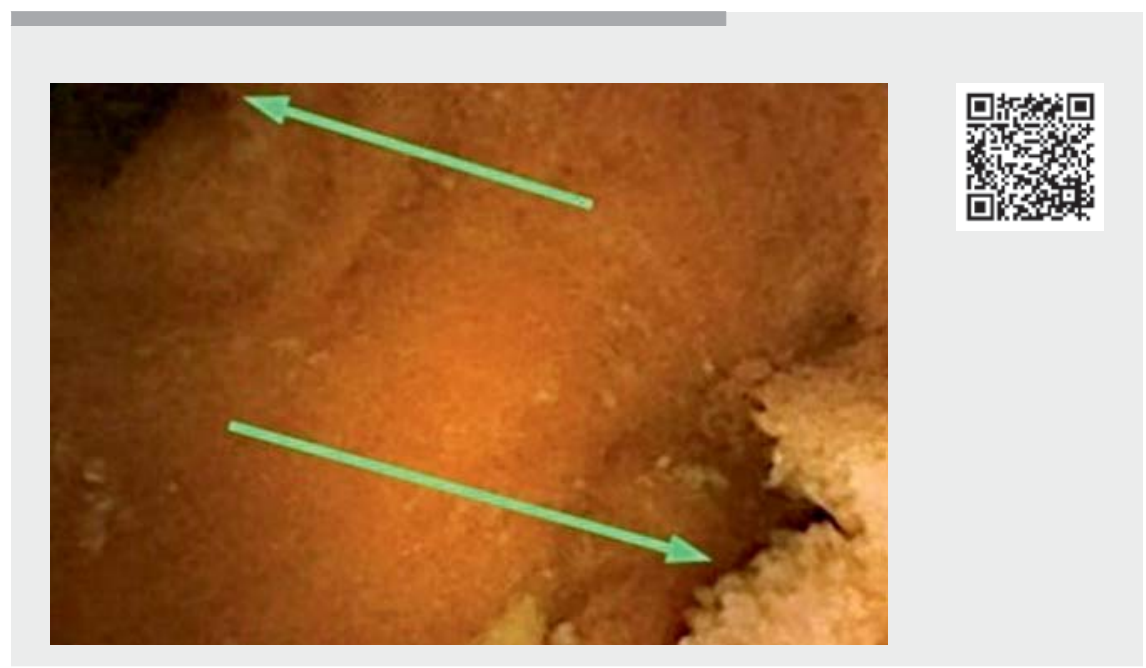

Video 1 Capsule endoscopy revealed a double lumen image in the ileum of a 54-yearold man. No active bleeding was found.

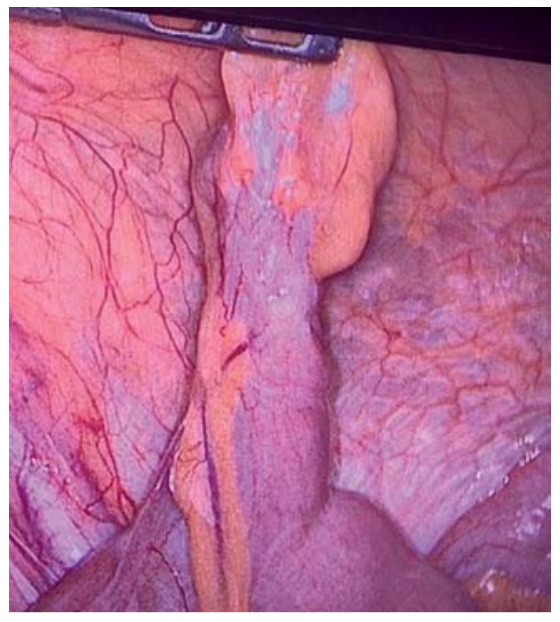

Fig. 1 Laparoscopic surgery revealed Meckel's diverticulum in the ileum, $40 \mathrm{~cm}$ proximal to the ileocecal valve.

\section{Competing interests}

The authors declare that they have no conflict of interest.

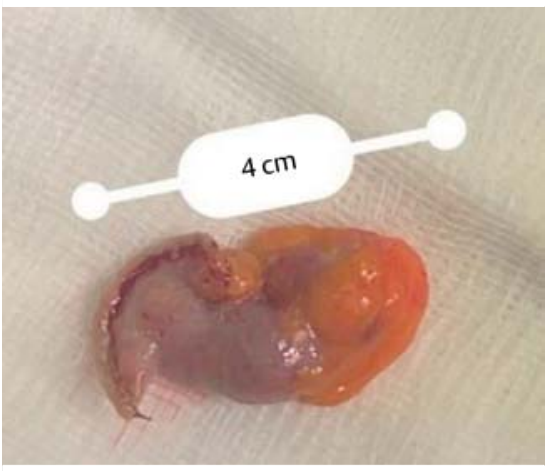

Fig. 2 Meckel's diverticulectomy: surgical specimen.

The authors

Ines Trucco ${ }^{1}$, Veronica Guido ${ }^{1}$, José Alvite ${ }^{1}$, Alexandra Duffau², Susana Reyes ${ }^{2}$, Carolina Olano ${ }^{1} \odot$

1 Clínica de Gastroenterología, Universidad de la Republica, Montevideo, Uruguay

2 Servicio Médico Integral, Montevideo, Uruguay 
Corresponding author

\section{Carolina Olano, MD}

Hospital de Clínicas, Av. Italia S/n CP,

11600 Montevideo, Uruguay

carolinaolanouruguay@gmail.com

\section{References}

[1] Lin L, Liu K, Liu H et al. Capsule endoscopy as a diagnostic test for Meckel's diverticulum. Scand J Gastroenterol 2019; 54: 122-127

[2] García D, Jiménez AR, Del Cueto ÁN et al. Meckel's diverticulum diagnosis by video capsule endoscopy: a case report and review of literature. World J Clin Cases 2018; 6 : 791-799
[3] Day NJ, Fultz P, Marino D. Recurrent smallbowel obstruction caused by a Meckel's diverticulum diagnosed on video capsule endoscopy. Clin Gastroenterol Hepatol 2016; 14: A21-A22

[4] Le Mouel JP, Morvan J, Fumery M et al. Meckel's diverticulum on third-generation video capsule endoscopy: intradiverticular ulcer, ectopic gastric mucosa, and active bleeding. Endoscopy 2018; 50: E205-E207

\section{Bibliography}

Endoscopy 2022; 54: E372-E373

DOI 10.1055/a-1540-6595

ISSN 0013-726X

published online 9.8.2021

(c) 2021. Thieme. All rights reserved.

Georg Thieme Verlag KG, Rüdigerstraße 14, 70469 Stuttgart, Germany
ENDOSCOPY E-VIDEOS

https://eref.thieme.de/e-videos

回屌 Endoscopy E-Videos is an

open access online section, 回: reporting on interesting cases and new techniques in gastroenterological endoscopy. All papers include a high quality video and all contributions are freely accessible online. Processing charges apply (currently EUR 375), discounts and wavers acc. to HINARI are available.

This section has its own submission website at

https://mc.manuscriptcentral.com/e-videos 